mit so großer Liberalität dem medizinhistorisch Forschenden immer zur Verfügung gestellte Bibliothek unseres unvergeßlichen Arnold C. Klebs, $\dagger$ am 6. März 1943 in Nyon, nach Kriegsende gelangen und durch ihre reichen Bestände an mittelalterlicher und Frührenaissanceliteratur die Sammlung seines Freundes Cushing (wie schon zu Lebzeiten beschlossen) in wertvollster Weise ergänzen. Mit dem Bedauern, daß diese wohl schönste medizinhistorische Bibliothek den Schweizerboden bald verlassen wird, sei die Hoffnung verbunden, es möchte auch bei uns sich jemand finden, welcher mit der gleichen Großzügigkeit und Liberalität sich um die Schaffung einer medizin-historischen Bibliothek verdient machen möchte, durch welche Forscher auf den Gebieten der historischen Medizin, Naturwissenschaft und Technik in den Stand gestellt würden, sich am Heben der so reichen literarischen Schätze unseres Landes, welche in vielen öffentlichen und privaten Bibliotheken der Schweiz ruhen, in ausgiebigerem Maße zu beteiligen, als dies bis heute möglich war. Solange ein gut ausgestattetes medizinhistorisches Zentrum in der Schweiz fehlt, wird auch der medizinhistorische Unterricht, der für den werdenden Arzt so reiche Bildungselemente enthält, nur ein untergeordnetes Dasein fristen können - dies in starkem Gegensatz zu den meisten europäischen Kulturstaaten, welche wie Schweden, Polen, Italien, Frankreich, Holland, Deutschland usw. medizinhistorische Forschung und Unterricht zum Teil in hervorragender Weise geför: dert und zu einem lebendigen Bestandteil der Kulturgeschichte ihres Landes entwickelt haben.

\title{
H. Fischer.
}

Johann Heinrich Lambert, Schriften zur Perspektive. Herausgegeben und ein. geleitet von Max Steck. 496 S. Dr. Georg Lüttke Verlag. Berlin 1943.

Zu den bedeutendsten Werken des großen Mathematikers J. H. Lambert, der sich selbst als «Mulhusino-Helveticus» bezeichnete und jüngerer Zeitgenosse Eulers war, gehört seine «Freye Perspektive», die 1759 gleichzeitig in deut. scher und französischer Ausgabe in Zürich bei Heidegger erschien. Dieses Werk, das 1774 eine zweite Auflage erfuhr, begründete die moderne Perspektive, und zwar ebenso in geometrischer wie in ästhetischer Richtung. Seit lan. ger Zeit ist das Buch jedoch vergriffen und leider auch in Ostwalds Klassikern der exakten Wissenschaften nicht neu aufgelegt worden. Es bedeutet daher ein großes Verdienst des deutschen Gelehrten, der als Dozent für Mathematik an der Technischen Hochschule und Universität München amtet, eine neue, reich dokumentierte und staatliche Ausgabe veranstaltet zu haben. Ein besonderes Verdienst liegt darin, daß er auch wertvolle, bisher unveröffentlichte Manuskripte Lamberts zur Perspektive anfügte (so die "Anlage zur Perspektive» von 1752, und «Kurzgefaßte Regeln zu perspektivischen Zeichnungen vermittelst eines zu deren Ausübung so wie auch zu geometrischen Zeichnun. 
gen eingerichteten Proportional-Zirkels» von 1768) und weiterhin erstmals eine vollständige Lambert-Bibliographie verfaßte, welche die Grundlage aller künftigen Lambert-Editionen bilden kann. ${ }^{1}$ In den manchmal etwas weitschweifigen und auch nicht immer richtigen Anmerkungen wird der Nachweis erbracht, daß Lambert der Erfinder des «Perspektographen» ist (S. 417 f.), sowie der «Reziprokenleitern» (womit er auch zu den Mitbegründern der Nomographie zählt). Grundlegendes hat Lambert weiterhin in der Fundierung der künstlerischen Perspektive geleistet; hier ist er kaum je übertroffen worden, und Steck hat in einem höchst eindrücklichen Kapitel «Lambert und die Kunst» die vielseitigen Beziehungen und Verdienste ins Licht gerückt.

In kurzem Rahmen wird der Reichtum der Steck'schen Arbeit nie voll zu würdigen sein; trotz einiger wohl durch die Zeitumstände bedingter Schönheitsfehler liegt hier einer der großen Beiträge zur Mathematikgeschichte des 18. Jahrhunderts vor, deren Zustandekommen unter erschwerten Umständen außerordentlich erfreulich ist. Die Lambert-Forschung ist um einen gewichtigen Schritt vorangekommen; die Schnyder-von-Wartensee-Stiftung hat daher den Autor auch mit Recht innerhalb ihres Preisausschreibens mit einem Teilpreis bedacht. Steck hat mitgeholfen, die von schweizerischen Mathematikern geplante Gesamtausgabe Lamberts zu fördern. ${ }^{2}$

Eduard Fueter.

\section{Erinnerung an Johann Babtista van Helmont (1579-1644) zu seinem 300. Todesjahr}

Der flämische 1579 in Brüssel geborene und 1644 in Vilvorde in Holland verstorbene Naturphilosoph, religiöse Mystiker, Paracelsusnachfolger, Alchemist und exakte Naturforscher Helmont war ein großer Entdecker auf dem Gebiete der Naturwissenschaften und der Medizin. Von ihm stammt eine der frühen Beschreibungen des Thermometers; er schlug eine neue Form der Zeitmessung mit Hilfe des Pendels vor. Als Biochemiker zeigte er, daß der Verdauungsprozeß im Magen sich in sauerem Milieu abspielt, im Dünndarm in alkalischem.

1 Die Bibliographie ist auch separat erschienen unter dem Titel: «Bibliographia Lambertiana», 74 S., Georg Lüttke Verlag, Berlin 1943.

2 Im Żeichen der Eroberung Mülhausens durch die deutsche Wehrmacht wurde unter dem Protektorat des Oberbürgermeisters auch eine nachträgliche Gedenkschrift zu Lamberts 200. Geburtstag herausgegeben «Johann Heinrich Lambert, Leistung und Leben» (Mülhausen 1944; $110 \mathrm{~S}$.), die gute, aber wenig originelle Zuasmmenfassungen und außerdem eine gekürzte Wiedergabe von Lamberts «Cosmologischen Briefen» enthält neben einigen ikonographischen Inedita und einer Ahnentafel. 